\title{
Voting Technology, Election Administration, and Voter Performance
}

\author{
Robert M. Stein, Greg Vonnahme, Michael Byrne, and Daniel Wallach
}

\begin{abstract}
In this paper we study the experience of individual voters on Election Day, November 2006, with two widely used voting technologies, optically scanned paper ballots and electronic voting machines. The focus of our empirical analysis is the relationship between voting technology and several dependent conditions, including voter satisfaction with their voting experience, the time it takes to vote, voter confidence that their ballot will be accurately counted, and self-reported undervotes. We find that a significant portion of the variation between the two voting technologies in voter behavior and affect is a function of election administration.
\end{abstract}

\section{INTRODUCTION}

$\mathbf{S}^{\mathrm{T}}$ TUDIES OF ALTERNATIVE voting technologies have shown that how voters cast ballots has a significant and independent effect on their behavior and affect toward the electoral process. The general finding is that some technologies tend to increase or decrease the likelihood that voters will fail to vote for some contests (undervotes) or err in marking their intended choices. But recent research suggests a significant portion of voter "error"1 at the ballot box is due to non-technological, jurisdictional-specific factors (Ansolabehere and Stewart 2005). The specific origins of this jurisdictional effect are largely unexamined in the extant literature.

In this article we test the efficacy of two dominant voting technologies-optically scanned

Robert M. Stein is The Lena Gohlman Fox Professor of Political Science, Rice University. Greg Vonnahme is a Ph.D. candidate in the Department of Political Science, Rice University. Michael Byrne is an associate professor of Psychology, Rice University. Daniel Wallach is an associate professor of Computer Science, Rice University. paper ballots and electronic voting machines (in particular, a touch screen machine manufactured by ES\&S) - in a setting that provides the advantages of a field experiment conducted with individual voters under Election Day conditions. We analyze the relationship between voting technology and several dependent conditions including voter satisfaction, the time it takes a voter to cast a ballot, voters' confidence that their ballots will be accurately counted, and self-reported undervotes.

In this article we take advantage of an unusual circumstance in which voters in the same election and in the same precincts were given a choice between two technologies.

\footnotetext{
${ }^{1}$ Several researchers eschew the term error, preferring to use the aggregate condition of undervotes to characterize the inconsistency between voter intent and the recording of that intent on the ballot. This latter choice is motivated by the view that there are several causes of this condition that are beyond the voter's control. Our use of the term, however, is not intended to suggest that the sole cause of error is the voter. We simply prefer to characterize the inconsistency between voter intent and the recording of that intent as an error (i.e., breakdown) in the electoral process.
} 
The resulting natural experiment is not an ideal one, because of the self-selection rather than a random assignment of voting technology by individual voters. Nevertheless, by enabling us to study the influence of differing technologies on voter behavior and affect while controlling for the differing administrative practices and personnel in the different precincts, our research setting provides a rare opportunity to study how alternative election technologies interact with precinct level administrative procedures and personnel to influence voter behavior and affect. We know of no other research that has studied the simultaneous use of two voting systems in the same polling place during Election Day voting. We find that polling places, their administration, and their personnel have a significant effect on voter behavior and affect toward voting systems, independent of the voting technology used by voters.

Our article proceeds with a brief review of the extant literature on voting technology and our own explanation and hypotheses for the effect of voting technology on voter behavior and affect. The third section provides a description of the research setting, our research design, and measures. The fourth section reports our findings and we conclude with a discussion in the final section of the policy implications of our findings.

\section{PREVIOUS RESEARCH}

The five voting technologies currently used in the United States are hand counted paper ballots, mechanical lever machines, punch cards, optically scanned paper ballots, and electronic voting machines (i.e., direct recording electronic voting machines, or DREs). The two most widely used technologies are optically scanned paper ballots and different types of DREs (Electionline 2007). Research has examined how each technology is related to several dependent conditions, including residual votes conventionally referred to as undervotes, voter satisfaction, voter confidence in the accuracy of the voting system, and the time it takes a voter to cast a ballot.

The residual vote is defined as the difference between the number of voters who come to the polls to vote and the number of votes cast in a given ballot contest. When the number of votes cast for any one race is less than the total number of ballots cast we observe residual votes, or undervotes. Overvotes occur when voters improperly mark or select more than one ballot choice for a single contest. These ballots are invariably voided with respect to the contest in question because voter intent cannot be readily determined.

The most obvious explanation of undervotes is the existence of weak and anemic candidate campaigns that fail to inform and mobilize voters, especially for low-level, obscure offices. Of greater relevance to election administration are undervotes that occur despite the voters' wish to register a choice for a given office. For example, new voting technologies, unfamiliar even to the most frequent voter, can lead voters to unintentionally fail to record their preferred vote choice. Overvotes in particular are most often attributed to ballot design, voting technologies, and the interaction of these factors with voter attributes (e.g., education, age, and related physical acuity). Here human factors interact with technology and ballot design to produce errors similar to those observed with the use and operation of consumer products (Greene, Byrne, and Everett 2006; Everett, Byrne, and Greene 2006; Laskowski et al. 2004; Roth 1998).

Using different methodologies (experimental and aggregate studies), research settings (precincts, cities, and states) as well as a mix of different voting technologies, the extant research has found that paper ballots, both hand counted and optically scanned, are significantly superior to lever machines, DREs, and punched cards in reducing the residual votes (Asher 1982; Shocket, Heighberger, and Brown 1992; Nichols and Strizek 1995; Knack and Kropf 2003; Kimball, Owens, and Keeney 2004; Ansolabehere and Stewart 2005). The congruity of these rankings, however, does not provide an unambiguous explanation for voting technology's effect on the residual vote. Conditions unique to each technology may interact with human factors and local election administration to influence the residual vote. Moreover, the actual influence of voting technology on residual votes may be exaggerated. Voters "may 
intentionally abstain in a particular race" (Ansolabehere and Stewart 2005:369) because of a lack of interest, information, or a preferred choice among the contesting candidates. These conditions cannot be attributed to any particular voting technology nor readily measured with aggregate/precinct level designs.

Ansolabehere and Stewart offer an important note of caution about their own and the extant literature's conclusions about the effect of voting technology on residual votes. "[I]t appears that most of what influences whether votes get counted is due to population dependent factors that are distinct from the type of voting technology used" (2005:383). They conclude:

The incidence of uncounted and spoiled ballots depends strongly and systematically on "county" in addition to equipment. ... We conjecture that this county effect is substantially the result of local institutions of electoral administration, such as the administration of local polling places or advance instruction to voters (2005:386).

We concur with this perspective and in this article we test the influence of local electoral administration on the incidence of undervotes and other electoral behaviors and attitudes.

The usability of a voting technology refers to both the efficient and timely manner with which voters cast their ballots and the voters' confidence and satisfaction with the voting technology (Brennan Center for Justice 2006). Poor usability can directly contribute to voter error and to an increase in residual votes. The literature on human factors and human-computer interactions identifies several principles for the design of voting technologies directed at improving the voting experience (Institute of Electrical and Electronics Engineers 2003). Among the metrics recommended for usability by the Federal Election Assistance Commission are a lower error rate for marking the ballot, efficient operation (time required to complete a ballot is not excessive) and satisfaction, meaning that voter experience is safe, comfortable, and free of stress, and instills confidence that the voter's ballot will be accurately counted (Election Assistance Commission 2005).
The empirical research on the usability of voting technology is limited to vendor-sponsored studies and a few scholarly studies, mostly focused on alternative electronic voting machines (Hernnson et al. 2005). Conrad et al. (2005) found that several DREs required many more actions by voters to cast their ballots, which increased the time to complete the voting process and lowered reported satisfaction with the voting experience. Curiously, the same authors find that DREs increase efficiency and voter confidence that their votes are accurately recorded, while reducing undervotes and distrust with the voting system. A recent review of the extant literature observed that "usability tests may be most valuable not in eliminating any one problematic feature of a system, but instead in evaluating the performance of a system as a whole and making clear the tradeoffs elections must consider in selecting a system" (Brennan Center for Justice 2006:104).

The tradeoffs between different technologies may be influenced by how elections are administered and the polling places at which they are held. There is evidence that the performance of different voting technologies is dependent on the quantity and quality of Election Day poll workers (Alvarez and Hall 2006; Hall, Monson, and Patterson 2007; Atkeson and Saunders 2007). The number of adequately trained Election Day workers may have a direct effect on voter usability, satisfaction, and confidence for different voting technologies. In addition, the place where one votes, including the proximity of the polling place to one's residence or work place, the availability of parking, and the ease of locating the polling place may structure a voter's experience with different voting technologies.

We expect that the influence of alternative voting technologies on voter affect and behavior will be mitigated by the quantity and quality of local election administration. In short, good policy implementation and administration can provide voters with an effective, efficient, secure, and usable election system, independent of the specific voting technology used. This is particularly true in the case of jurisdictions that adopt a new voting technology. Here administrative support staff and polling place operations can be critical in assisting voters un- 
familiar with the new voting procedures. In this instance, effective administration can reverse or at least mitigate a voter's negative experience with a new voting technology.

We hypothesize:

$\mathrm{H}_{1}$ : Effective electoral administration will be negatively related to the incidence of voter undercounts.

$\mathrm{H}_{2}$ : Effective electoral administration will be positively related to voters' confidence in the accuracy with which their ballots will be counted.

$\mathrm{H}_{3}$ : Effective electoral administration will be positively related to the voter's ratings of the ballot system used.

$\mathrm{H}_{4}$ : Effective electoral administration will be negatively related to the time it takes to cast a vote.

\section{RESEARCH SETTING AND MEASURES}

Research on the efficacy and efficiency of alternative voting technologies has been conducted in either an experimental/laboratory setting or at the precinct level where aggregated voting behavior is observed under different voting technologies. Each research strategy has its own strengths and weaknesses. Experimental research provides strong controls for rival explanations but often is unable to replicate the vote choices individuals make on (or before) Election Day, lessening our confidence in the generalization of experimental findings. Aggregate level studies of precinct voting provide a valid measure of voter behavior but are unable to adequately control for rival explanations, most notably demographic attributes of individual voters. (Shocket et al. 1992). Another omitted variable in most research on the impact of voting technology is the administrative structure and support voters receive at their respective voting places on Election Day.

To test our central thesis we collaborated with the County Clerk of Jefferson, Texas to evaluate two different voting technologies used on Election Day November 6, 2006. Previous to the 2006 mid-term election scanned paper ballots were used in Jefferson County elections. As part of a program to evaluate a new voting system, Election Day voters in Jefferson County were given a choice between a touch screen voting machine manufactured by ES\&S or a scanned paper ballot. ${ }^{2}$ We interviewed a sample of Election Day voters about their voting experience $(\mathrm{N}=526)$ as they left their polling places. ${ }^{3}$ We constructed several measures of self-reported voter behavior and affect including a scale score that measures the usability of the voting system, a scale score that measures the usability of the polling place, selfreported undervotes, self-reported time it took to vote, and voter confidence in the integrity of the voting system. In addition, we collected information on self-reported voting history, prior experience with each type of voting technology, and selected demographics, namely age, income, education, and partisan affiliation.

\section{Descriptive summaries}

Before discussing the hypothesis tests, it might be useful to discuss which ballots the voters' chose on Election Day. $82.5 \%$ of our randomly selected voters reported using the DREs. ${ }^{4}$ This finding was notable not only for the large proportion of voters that reported using the DREs, but also for how consistent the rates were across different demographic groups. Figure 1 displays the proportion of voters that reported using the DRE across gender, race, education, and partisan categories.

Regarding gender, there was little difference as more than $80 \%$ of both sexes reported using DREs, with approximately $1.8 \%$ more males using an electronic ballot. There was slightly more variation across racial groups, although the samples were small for some of these groups. The asterisks in Figure 1 indicate that less than 5\% of the data (fewer than 25 observations) fall into

\footnotetext{
${ }^{2}$ In-person early voting in Jefferson County was conducted on touch-screen DRE voting machines manufactured by ES\&S.

${ }^{3}$ Voters were interviewed at 19 of 91 polling places in Jefferson County.

${ }^{4}$ We cannot attribute this skewed distribution to the unequal availability of DREs and paper ballots at each polling place. With the exception of one precinct, there were an equal number of touch screen and paper ballot voting stations available at each of the voting precincts at which we conducted exit polling.
} 
that category. Focusing on the larger samples, there is a difference between black and white voters, with approximately $8 \%$ more whites reporting use of a DRE. While black voters reported using DREs at a somewhat lower rate relative to whites, they nevertheless reported using a DRE three to one over a paper ballot.

The other categories also show some variation in DRE usage. Individuals reporting having less education also used DREs at a lower rate, although interviewees with a graduate degree were slightly less likely to report using a DRE that those with an undergraduate degree. Interviewees with a grade school education were the least likely to use a DRE, although this group was particularly small $(n=5)$. Democrats were also less likely to use a DRE than those who identified as Republican, Independent, or Other (the numeric difference between Democrats and Republicans was $11.91 \%$ ), but again, over $75 \%$ of Democrats chose the DRE over a paper ballot.

Figure 2 shows the distribution of age across ballot usage. From this figure, we can see that DRE users were slightly younger than those who used paper ballots, but this difference is small, with a substantial amount of overlap in the age of paper and electronic ballot users. We also examined whether or not there is evidence that those with greater experience using other types of technology might be more likely to choose electronic over paper ballots. We com-

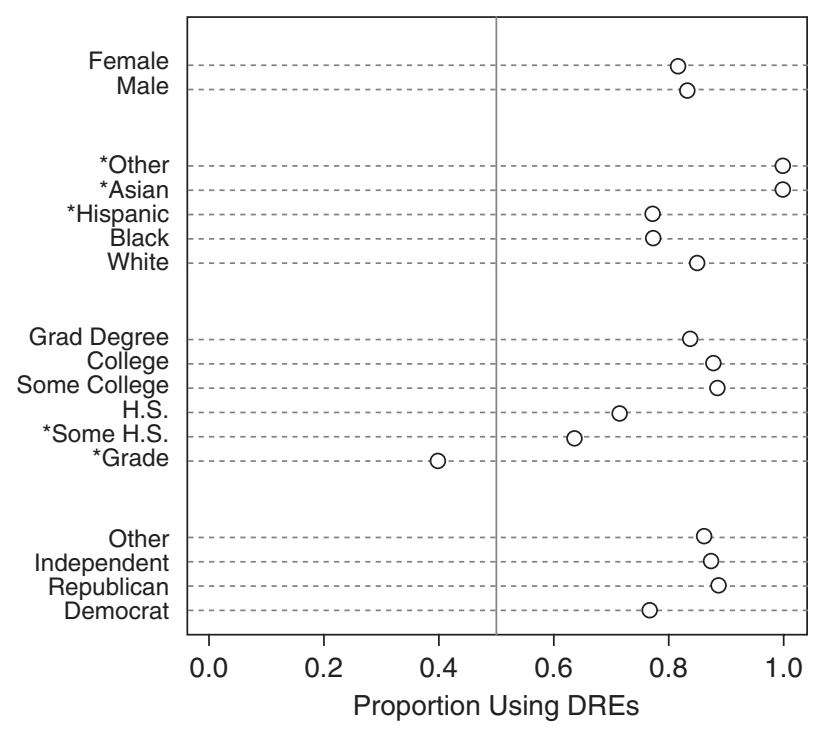

FIG. 1. Who used the DRE's?

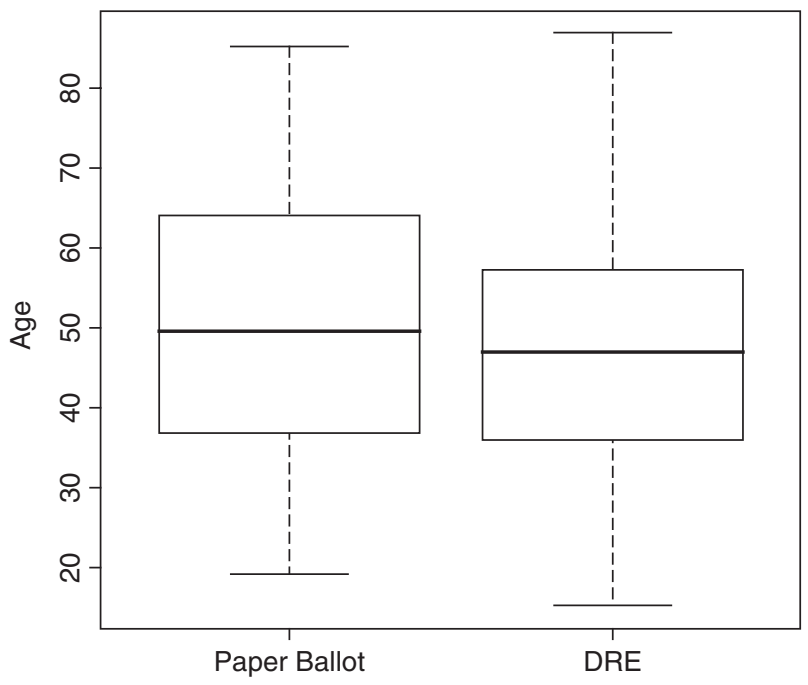

FIG. 2. Ballot choice and age.

pared respondents that reported using a computer at home or work, and those that reported using ATMs. The results are shown in Figure 3 . The differences are approximately $13 \%$ for computer users, and 11\% for ATM users, although again, more than $70 \%$ of each group chose the electronic over paper ballot.

This initial analysis is useful as it provides information as to which type of ballot the voters themselves will choose. Additionally it helps us to determine if there is an identifiable subpopulation of voters who are especially likely to choose one type of ballot over another. There does not seem to be evidence of such subpopulations, at least in Jefferson County, Texas.

\section{Selection issues}

Our primary interest in this article is the influence of alternative voting technologies and of different precincts on voter ratings of usability, time to vote, voters' confidence that their ballots will be counted, and undervotes. The major advantage of the data we draw on is that we can compare the survey evidence using two forms of technology in the same precincts. ${ }^{5}$ The major drawback of our data is

\footnotetext{
${ }^{5}$ We have no reason to believe there might have been a poll worker effect on the ballot voters chose on Election Day. According to Jefferson County Clerk Carolyn Guidry, poll workers at each polling place were responsible for supervising and assisting voters with both paper and DRE ballots.
} 


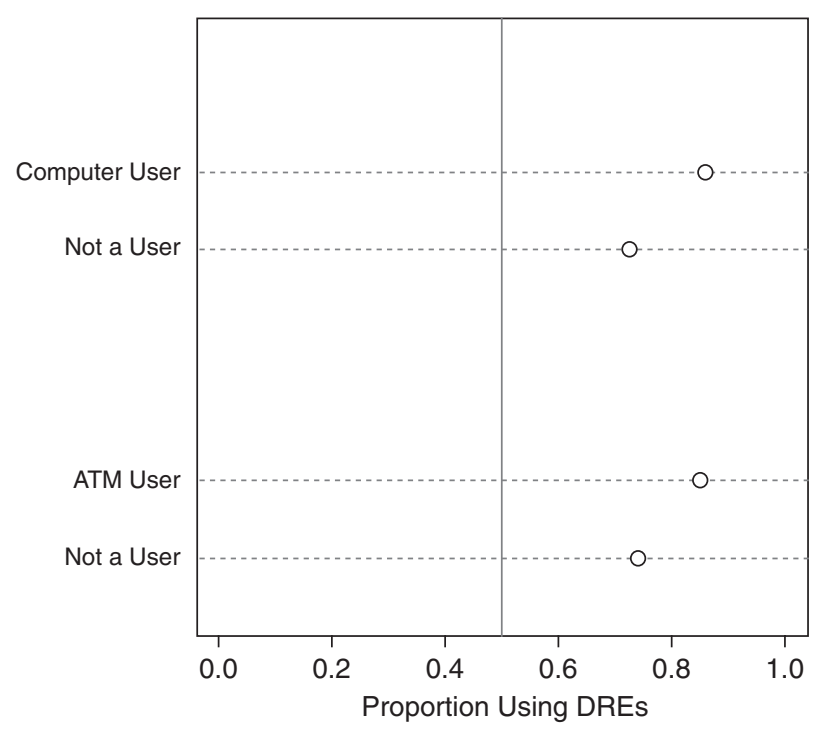

FIG. 3. Digital divide in DRE use.

that the voters using the different technologies were self-selected. That is, voters were allowed to choose between a DRE and paper ballot at the polling sites. This introduces the possibility that some unobserved factor is related to both the voters' choice of ballot type and the outcome variables of interest, thus confounding the results.

The selection bias cannot be eliminated as a concern, but there are several mitigating considerations. The first is that, as we have already seen, the DRE and paper ballot users are similar to one another on a range of factors, such as age, gender, and education. While this does not preclude the possibility that the groups differ on some other factor, it provides some indirect reassurance that the groups do not differ substantially on factors that would be related to those discussed above.

The second is that while the voters choosing DREs might be relatively predisposed to evaluate the DREs favorably, we are comparing how voters who chose DREs evaluated the DREs, with how voters who chose paper ballots evaluated paper ballots. Selection bias is mitigated because the predisposition of DRE users to rate the DREs favorably should be offset by a similar predispotision of paper ballot users to evaluate the paper ballot favorably. While the absolute scales for DRE and paper ballots might appear more positive than if we had data for the full population of voters, we can nevertheless compare the two to determine which was rated more highly. That is, unobserved factors might lead to better ratings of the ballots, which is a reason to be cautious about interpreting the scales individually, but would be less likely to affect the comparison of the two ballot types unless the unobserved variable was a stronger factor for those who selected one method than for those who selected the other. Although this is possible, there is no apparent reason that it is likely.

As discussed above, we did not find that paper ballot users were significantly older, less educated, imbalanced between males or females, or different from DRE users on any other factor. While DRE users were far more common in our data, they were also comparable, on average to those that reported using paper ballots. Moreover, a higher percentage of voters who chose a scanned paper ballot $(57 \%)$ over the touch-screen voting machine $(45 \%)$ reported using this type of voting system before. ${ }^{6}$ The selection bias, if any, appears to work against the DRE and in favor of the scanned paper ballot.

The absence of any significant demographic differences between the users of paper ballots and DREs does not mean there is no selection bias in the data. Without random assignment of voters to the alternative election systems, it is difficult to rule out the possibility that there are imbalances between the groups on unobserved factors. Moreover, there remains the possibility that these unobserved determinants of ballot selection have an independent effect on reported voter behavior and after. Caution should be taken with our findings, by considering them together with existing and future research.

\section{Measures and analyses}

To measure the usability of voting systems, we asked voters whether they agreed or dis-

\footnotetext{
${ }^{6}$ The chi-square for this relationship is significant at the .05 level. To control for the potential effect of prior use of each voting system we include in our models of voter behavior and affect the voter's prior use of the selected voting technology. Specifically, voters were asked, "have you ever used this type of machine before?" More than half $(53 \%)$ of our sample of Election Day voters reported "yes" to this question.
} 
agreed with the following statements about the voting technology they used on Election Day. ${ }^{7}$

- I thought the system was easy to use.

- I think that I would like to use this system again.

- I found the voting system unnecessarily complex.

- I think that I would need the support of a technical person to use the system.

- I felt very confident using the system.

- I need to learn a lot of things before I could get going with the system.

A factor score was calculated for the six items using an unrotated principal components analysis. ${ }^{8}$ A similar set of questions was posed to voters about their polling place:

- This location was easy for me to find.

- I did not have to go far out of my way to vote.

- It was easy for me to find a place to park.

- The poll workers were helpful.

Again a factor score was computed for four items using an unrotated principal components analysis. $^{9}$

Our measure of undervotes is based on a voter's response to the question: "In about how many races did you vote today?" Voters could respond that they voted in all, more than half, half, or less than half of the races. Those who reported not voting in all races were coded as having knowingly undervoted. The official undervote in the Jefferson County, Texas 2006 mid-term election was $16 \%$. This figure is based on the difference in the number of votes cast for the U.S. Senate (i.e., the first race on the ballot) and for the County Criminal Court Position \#1, the last race on the Jefferson County ballot. The self-reported under count among our sample of Jefferson county voter was $20 \%$.

Our measure of undervotes is not directly comparable to the aggregate measure obtained from the official canvass. The latter measure of undervotes includes uncounted ballots that arose from errors made by the voter as well as any errors caused by the voting technology used and other errors in electoral administra- tion. Our self-reported measure of under counts represents what voters recall about the completeness of their ballots. Our inference about the hypothesized relationship between self-reported undervotes and voting technology is that the usability of the voting technology, independent of other reasons for undervotes (e.g., voter indifference and low salience for some races), influences the likelihood a voter will or will not vote in all races. We are able to test the effect of voting technology on undervotes against alternative explanations for this condition including voter interest, salience, and experience with the inclusion of control measures for these explanations in our model of undervotes.

We assessed voter confidence in the voting system with the question: "I am confident that my vote will be counted accurately." Voters were asked if they agreed or disagreed with this statement using a five point scale $(1=$ strongly disagree and $5=$ strong agree). A majority of voters (66\%) strongly agreed with the statement.

Finally, we asked voters "how long did it take you to vote?"10 The modal response to this question was less than five minutes. A significantly larger proportion of voters using the touch screen voting machine $(84 \%)$ reported taking less than five minutes to vote than was reported by voters who voted on a paper ballot $(78 \%) .{ }^{11}$ As a check on the actual time it took voters to use each type of system we located poll watchers in each of our 19 precincts who

${ }^{7}$ Voters were asked whether they agreed or disagreed with each statement on a scale of one to five, where one indicated "disagree strongly" and five indicated "agree strongly."

${ }^{8}$ A factor analysis of the six items produced only one dimension with an eigenvalue greater than 1.0. This factor accounts for $50 \%$ of the variance in the six items. Factor analysis is used to test the unidimensionality of our scale and to construct a scale score. Bivariate correlations among scale items is used to test the unidimensionality of our scale and to construct the individual scale scores. ${ }^{9}$ A factor analysis of the four items produced one factor with an eigenvalue greater than 1.0. This factor accounts for $73 \%$ of the variance in the four items.

10 The response set to this question was: (1) less than 5 minutes (2) 5-10 minutes (3) 11-15 minutes and (4) more than 15 minutes.

11 The chi-square for this relationship is significant at the .01 level. 
Table 1. Hypothesized Relationships

\begin{tabular}{|c|c|c|c|c|}
\hline Independent variable & Usability & Undervote & Confidence & Time to vote \\
\hline $\begin{array}{l}\text { Voting system } \\
\qquad(1=\text { DRE, } 0=\text { Paper })\end{array}$ & + & + & - & + \\
\hline Rating of ballot type & - & NA & + & + \\
\hline Rating of polling place & - & + & + & + \\
\hline Prior use of vote system & - & + & + & + \\
\hline Non-Anglo & + & - & - & - \\
\hline $\begin{array}{l}\text { Partisan voter } \\
\qquad(1=\text { Dem. or Rep.; } 0=\text { Ind, })\end{array}$ & + & + & + & - \\
\hline Prior voting history & - & - & + & + \\
\hline Undervote & NA & NA & NA & + \\
\hline Age & - & - & + & + \\
\hline Education & - & - & + & + \\
\hline Income & + & + & + & - \\
\hline
\end{tabular}

timed a sample of voters on each of the voting machines used on Election Day. On average, voters using a DRE took two minutes and 55 seconds to ballot. Voters who chose a paper ballot required three minutes and 44 seconds to complete their ballot. The observed difference in time to vote with each voting technology is statistically significant $(\mathrm{p}<.002) .{ }^{12}$

Table 1 summarizes the hypothesized relationships between selected independent and dependent variables. In most instances our source for these expected relationships is the extant literature reviewed above. Several of our hypotheses, however, are untested in the literature. ${ }^{13}$ To address a concern that there is significant unobserved heterogeneity driving our results we have reported robust standard errors clustered on polling place in each of our regression models.

Table 2. Descriptive Statistics by Ballot Type

\begin{tabular}{lcc}
\hline & \multicolumn{2}{c}{ Ballot } \\
\cline { 2 - 3 } Measure & Paper & DRE \\
\hline Rating of Ballot (range: 5-30) & 22.2 & 25.9 \\
Proportion reporting under count & 0.16 & 0.2 \\
Voter confidence (range: 1-5) & 4.2 & 4.3 \\
Proportion taking $<5$ min. to vote & 0.78 & 0.84 \\
\hline
\end{tabular}

\section{FINDINGS}

Table 2 reports the descriptive statistics for each of our dependent variables by ballot type. Voters rated the DRE ballot more usable than voters who used the paper ballot. Though both ballot technologies received favorable ratings from a majority of their respective users, the difference in ratings is significant $(\mathrm{P}<.001)$ and

12 Poll watchers timed 596 voters in 19 precincts as they voted on scanned paper ballots $(\mathrm{N}=130)$ and the touch screen voting machines $(\mathrm{N}=442)$.

13 A fixed effects model was attempted, where 1-n number of dummy variables, one for each voting place, was included in each of our models. The advantage of this technique is to control for unmeasured and confounding variables operating at the level of the voting place. This procedure, however, was not possible to execute because of the previously discussed one-sidedness in the type of ballot chosen by our respondents. As noted, over $82 \%$ of our sample chose a DRE ballot. At a number of voting places there were fewer than two respondents (and in one instance no respondents) who used a paper ballot. This distribution and the inclusion of ballot type in all our models made it impossible to estimate our models with the inclusion of a separate dummy measure for each voting place. We do not consider this problem serious. Our models include what we believe to be most if not all of the theoretically relevant confounding variables that are operating at the level of voting place, including the voters' ratings of their voting places. This factor score includes specific items about the workers at each voting place, location-specific questions about the ease of finding the voting place, parking and ease of voting. 
Table 3. Regression Estimates for Voter Rating of Ballot Technology $(\mathrm{N}=375)^{*}$

\begin{tabular}{lrrrr}
\hline Variable & \multicolumn{5}{c}{$\begin{array}{c}\text { Rbst } \\
\text { Std } \\
\text { Err }\end{array}$} & \multicolumn{1}{c}{$T$} & $P$ \\
\hline Constant & -.480 & .345 & -1.39 & .165 \\
Ballot type & .587 & .157 & 3.73 & $.000^{* *}$ \\
Prior use of ballot type & -.020 & .083 & -.24 & .809 \\
Rating of polling place & .444 & .061 & 7.26 & $.000^{* *}$ \\
Anglo & .307 & .103 & 2.96 & $.003^{* *}$ \\
Partisan & -.095 & .092 & 1.04 & .300 \\
Prior voting history & -.051 & .051 & -1.00 & .318 \\
Age & -.006 & .003 & -1.82 & .069 \\
Education & .046 & .045 & 1.02 & .310 \\
Income & .072 & .031 & 2.28 & $.023^{* *}$ \\
\hline
\end{tabular}

${ }^{*}$ r-square $=.371 ;{ }^{* *} \mathrm{p}<.05$

clearly favors the touch screen DRE. Voters' confidence that their ballots were accurately recorded does not vary by ballot technology used. Reported ballot undervotes are slightly higher among voters who used the touch screen voting machine $(20 \%)$ than among paper ballot voters $(16.5 \%)$. Though the direction of this finding is consistent with findings reported in the literature, the observed difference in reported undervotes between ballot types is not statistically significant at conventional levels of probability. Finally, we detect a weak relationship between time to vote and ballot type. As expected, touch screen users reported casting a ballot faster ( $84 \%$ reported under five minutes) than paper ballot voters $(78 \%$ under five minutes), though this difference is significant only at the .1 level of probability.

These observed differences in voting behavior and affect by ballot type could be spurious and related to human factors and administrative activities. To test for the independent effect of ballot type on voting behavior and affect we report estimates from several models of reported voting behavior and affect below.

\section{Usability}

Table 3 reports the regression estimates for our model of ballot usability. ${ }^{14}$ The main independent variables of interest are ballot type $(1=\mathrm{DRE}, 0=$ Paper), prior use of ballot type
$(1=$ Yes, $0=\mathrm{No})$, and usability scale score for voting place. ${ }^{15}$

Electoral administration has an independent and strong effect on how voters evaluate the two ballot systems. A positive evaluation of one's voting place and its personnel has a substantial positive effect on the voter's evaluation of the voting system used on Election Day. This effect appears to operate for both DREs and paper ballot. Regardless of the ballot system used, voters are significantly more likely to have a favorable rating of the ballot used on Election Day if the voters positively rated their polling place and its administration. This finding,

${ }^{14}$ Huber-White robust standard errors clustered on voting place are used in our estimates to correct for any heteroskedasticity in our models.

${ }^{15}$ We also examined the possibility that ballot effects on usability and voter affect are conditioned by the quality of electoral administration. Substantively we include this interaction because we believe there is a strong possibility that the impact of the balloting mechanism on voters' behavior and evaluations is significantly affected by their experience at the polling place. We think this effect is particularly important for the newer and more technologically challenging DRE balloting system. To test for this possibility we included in our models the interaction between ballot type $(1=\mathrm{DRE}, 0=$ Paper $)$ and usability of voting place. We hypothesize that effect of ballot type on voters' satisfaction with ballot system is conditioned by their evaluation of their experience at the voting place. The coefficient for the interaction between ballot type and voter rating of the polling place is statistically insignificant for all of our models. 


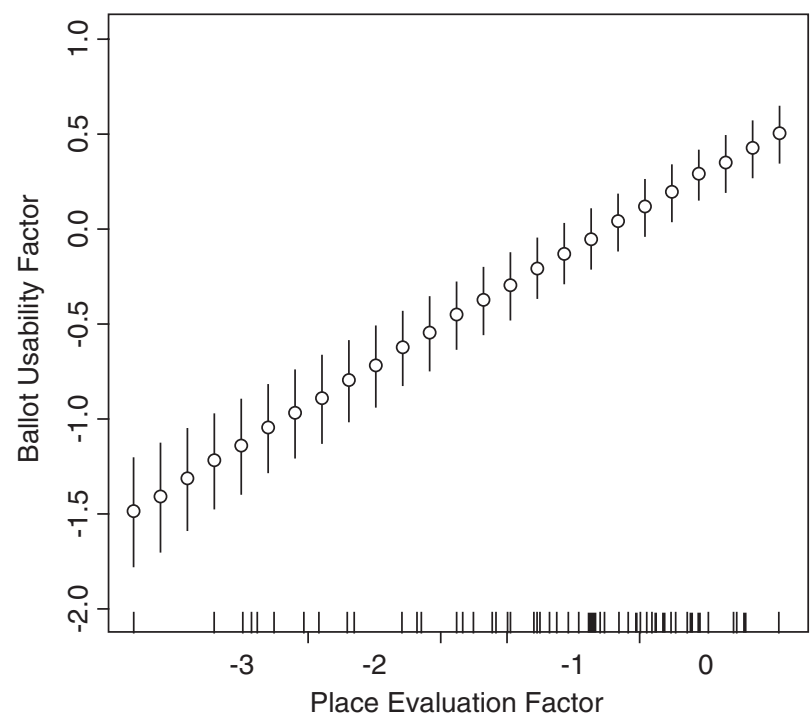

FIG. 4. Ballot evaluation by polling place evaluation.

which is consistent with our first hypothesis and the explanation offered by Ansolabehere and Stewart (2005), is shown graphically in Figure 4 . From this figure, we can see that evaluations of the ballots increase over polling place evaluations and that there is no overlap in the $90 \%$ confidence intervals from lower to higher values of place evaluation. A rug plot is included at the bottom of the graph to show the frequency distribution of the data over the range of values of the place evaluation factor. Income has a positive effect on voter ratings of each ballot system. Non-Anglos are more likely to have a lower rating of both ballot systems than Anglo voters, a finding that confirms previous research (Tomz and Houweling 2003).

\section{Undervotes}

Table 4 reports the logit regression estimates for a model of undervotes in the 2006 mid-term election. Several variables are included in our model to account for alternative explanations of undervotes that are mentioned in the literature. A key procedure that can minimize undervotes is straight ticket voting. In Texas, as in many other states, loyal partisans can choose to select an option that casts their votes for all Democratic or Republican candidates. We expect selfidentified partisans, either Democrats or Republicans, to be more likely to cast a straight ticket ballot and therefore less likely than independents to cast an incomplete ballot. Similarly, older, educated, and experienced voters (i.e., those who report voting in most elections) are expected to cast a complete ballot.

Neither ballot type nor its prior use has a significant effect on the incidence with which voters reported casting an incomplete ballot. Interestingly, however, voter ratings of the usability of their ballot were positively related to the incidence of self-reported complete ballots. Voters who positively rated their ballot, both paper and DRE, were significantly more

Table 4. Logit Regression Estimates for Incidence of Self-Reported UndERVOTE $(\mathrm{N}=375)^{*}$

\begin{tabular}{lrrrr}
\hline & \multicolumn{5}{c}{$\begin{array}{c}\text { Rbst } \\
\text { Std } \\
\text { Variable }\end{array}$} & Coeff. & Err & $Z$ & $P$ \\
\hline Constant & -.974 & 1.01 & -.96 & .337 \\
Ballot type & .301 & .462 & .65 & .515 \\
Prior use of ballot type & -.318 & .282 & -1.13 & .259 \\
Rating of ballot & -.316 & .166 & -1.90 & .057 \\
Rating of polling place & .034 & .163 & .21 & .832 \\
Anglo & -.295 & .345 & .85 & .393 \\
Partisan & .286 & .357 & .80 & .423 \\
Prior voting history & .437 & .137 & 3.19 & $.001^{* *}$ \\
Age & -.032 & .009 & -3.31 & $.001^{* *}$ \\
Education & .114 & .149 & .76 & .446 \\
Income & -.140 & .095 & -1.47 & .141 \\
\hline
\end{tabular}

*Pseudo r-square, .106; ${ }^{* *} \mathrm{p}<.05$ 
Table 5. Logit Regression Estimates for Time to Vote $(\mathrm{N}=375)^{*}$

\begin{tabular}{lcccc}
\hline Variable & \multicolumn{5}{c}{$\begin{array}{c}\text { Rbst } \\
\text { Std } \\
\text { Err }\end{array}$} & $\mathrm{Z}$ & $P$ \\
\hline Constant & -2.03 & .866 & -.235 & $.019^{* *}$ \\
Ballot type & -.703 & .399 & -.176 & .078 \\
Prior use of ballot type & .085 & .303 & .28 & .778 \\
Rating of ballot & -.049 & .182 & -.27 & .788 \\
Rating of polling place & -.319 & .159 & -2.00 & $.046^{* *}$ \\
Anglo & .010 & .346 & .03 & .976 \\
Partisan & -.810 & .354 & -2.29 & $.022^{* *}$ \\
Prior voting history & .386 & .151 & .255 & $.011^{* *}$ \\
Age & .010 & .009 & 1.13 & .259 \\
Education & .020 & .144 & .15 & .884 \\
Income & -.196 & .112 & -1.74 & .081 \\
Undervote & .958 & .309 & 3.18 & $.001^{* * *}$ \\
\hline
\end{tabular}

*Pseudo r-square, $.110 ;{ }^{* *} \mathrm{p}<.05$

likely to report casting a complete ballot. However, the magnitude of the effect of ballot usability on reported undervotes is modest. We observe a .09 increase in the likelihood of voters casting complete ballots as their evaluation of ballot usability increases from one standard deviation below the mean usability score to one standard deviation above.

The incidence of reported undervotes is negatively related to age and prior voting experience, as expected, but not education. Partisans are more likely to report casting complete ballots, but this relationship is significant only at .1 level of probability. Older and experienced voters are significantly more likely to complete their ballot. Presumably, politics is sufficiently more salient for older and experienced voters to enable and motivate them to cast a complete ballot.

\section{Time to vote}

Table 5 reports the logit regression estimates for our measure of time to vote $(0=$ less than 5 minutes and $1=$ more than five minutes). There is no evidence that ballot system or ballot usability positively affects the time it takes a voter to ballot. As expected, voters who positively rated their polling place and its administrative personnel were significantly more likely to report casting a ballot faster than those who neg- atively rated their polling place personnel and operations. Presumably, access to the polling site, ample parking, and helpful poll workers facilitate the time voters take to ballot, independent of the ballot used. Voters who reported voting frequently, independent of the ballot system used, reported voting significantly faster than those who reported voting infrequently. Similarly, wealthier voters reported voting faster, as did those casting an incomplete ballot.

\section{Voter confidence}

Table 6 reports the estimates of voters' confidence that their ballots were accurately counted. Rating of electoral administration, partisanship, prior voting history, and voters who reported casting a completed ballot are significantly and positively related to voter confidence. The insignificant coefficient for ballot type demonstrates that voter confidence is not dependent on ballot type, but rather on the voter's experience with the ballot, either DRE or paper. Electoral administration has a stronger effect on voters' confidence that their ballot will be counted accurately than voters' perceptions about the usability of their ballot system, further supporting our hypothesis that electoral administration dominates ballot effects on voter confidence. 
Table 6. Regression Estimates for Voter Confidence Their Ballot Was Counted ACCurately $(\mathrm{N}=375)^{*}$

\begin{tabular}{lcccc}
\hline Variable & Coeff. & $\begin{array}{c}\text { Rbst } \\
\text { Std } \\
\text { Err }\end{array}$ & $T$ & $P$ \\
\hline Constant & 4.72 & .270 & 17.5. & $.000^{* *}$ \\
Ballot type & .061 & .137 & .45 & .654 \\
Prior use of ballot type & .124 & .077 & 1.59 & .112 \\
Rating of ballot & .931 & .060 & 15.3 & $.000^{* *}$ \\
Rating of polling place & .115 & .061 & 1.89 & .059 \\
Anglo & -.029 & .087 & .34 & .733 \\
Partisan & .097 & .079 & -1.23 & .221 \\
Prior voting history & .009 & .045 & -.21 & .834 \\
Age & -.004 & .002 & -1.69 & .092 \\
Education & -.050 & .045 & -1.12 & .265 \\
Income & -.017 & .028 & -.61 & .545 \\
\hline
\end{tabular}

*Pseudo r-square, .634; ${ }^{* *} \mathrm{p}<.05$

\section{DISCUSSION}

Contrary to previous research, we fail to identify a consistent, significant, and independent effect for ballot type on voter behavior and affect toward the electoral system. The exception is in voters' ratings of the usability of each ballot system. Here we do find that voters rated the touch screen DRE as more usable than the paper ballot. Even in that case, though the DRE received a superior rating from voters, both systems were favorably rated by more than $60 \%$ of their respective users.

As suggested by Ansolabehere and Stewart (2005), we find electoral administration has a significant and independent effect on voter behavior and affect. Voters who rated their Election Day polling place highly and the poll workers as helpful were significantly more likely to favorably rate the voting system they used, were more confident that their ballot was counted accurately, and took less time to complete their ballot. The exception to this finding is self-reported undervote. Here we find that ballot usability and not a voter's rating of the polling place is significantly related to casting a complete ballot. This effect, however, is both modest and overshadowed by several alternative explanations in the literature, including the salience of the race and the voter's interest in and attentiveness to politics, as indicated by prior voting history, age, and partisanship.

The finding that electoral administration influences voter behavior and affect toward the electoral system may not seem to be a novel finding. Clearly our conclusion is suggested in Ansolabehere and Stewart's work and more recently by Alvarez and Hall (2005) and Hall et al. (2006). Given our research setting, however, the finding may be suggestive of how important electoral administration is to the implementation of new voting systems. Recall that previous to the 2006 election all voting in Jefferson County, Texas, had been conducted on paper ballots. Consequently, the introduction of touch screen DREs as an option alongside paper ballots was both novel and presumably unfamiliar to most voters in the county. Moreover, an overwhelming majority of voters chose to vote on the new DRE machines. It would have been reasonable to suspect that these conditions would lead to voter confusion and frustration with the new and presumably unfamiliar voting equipment. As demonstrated above, the opposite was true.

Election administration and the personnel who are charged with conducting elections encompass a wider range of factors than are discussed in this article and the extant literature. Neglected in this discussion is the location and configuration of polling places. We suspect that 
where people vote, specifically its proximity to work and home, as well as the availability of parking and number of voting machines has a significant impact on the voting experience. If, as we have demonstrated, election administration matters, future research should focus on these physical attributes of polling places as potential determinants of voter behavior and affect.

\section{ACKNOWLEDGEMENT}

The authors wish to acknowledge the assistance of Lillie Coney, Associate Director of the Electronic Privacy Information Center and Carolyn Guidry, Clerk, Jefferson County, Texas.

\section{REFERENCES}

Alvarez, R. Michael and Thad E. Hall. 2006. "Controlling Democracy: The Principal-agent Problems in Election Administration," Policy Studies Journal. 2006. 34, 4:491-510.

Ansolabehere, Stephen and Charles Stewart III. 2005. "Residual Votes Attributable to Technology," Journal of Politics, 67:365-389.

Asher, Herb. 1982. “The Effect of Voting Systems on Voter Participation." Presented at the annual meeting of the Midwest Political Science Association, Milwaukee, Wisconsin.

Atkeson, Lonna and Kyle Saunders. 2007. Election Administration and Voter Confidence: A Local Matter. Manuscript. University of New Mexico.

Brennan Center for Justice. 2006. The Machinery of Democracy: Voting System Security, Accessibility, Usability and Cost. New York University, New York.

Conrad, Fred et al. A Laboratory Evaluation of Six Electronic Voting Machines available at <http://www.upassoc. org/usability_resources/conference/2005/Conrad. ppt>.

Election Assistance Commission. 2005. Voluntary Voting System Guidelines available at <http://www.eac.gov/ docsEAC\%20Testimony.pdf $>$.

Electionline. 2007. Election Voting Systems as of 2006 available at <http://electionline.org/Default.aspx? tabid $=1099>$.

Everett, S. P., Byrne, M. D., and Greene, K. K. (2006). "Measuring the usability of paper ballots: Efficiency, effectiveness, and satisfaction." To appear in Proceedings of the Human Factors and Ergonomics Society 50th Annual Meeting. Santa Monica, CA: Human Factors and Ergonomics Society.
Greene, K. K., Byrne, M. D., and Everett, S. P. (2006). A comparison of usability between voting methods. To appear in Proceedings of the 2006 USENIX/ACCURATE Electronic Voting Technology Workshop.

Hall, Thad, Quin Monson, and Kelley Patterson. 2007. "Poll Workers in American Democracy: An Early Assessment." Manuscript.

Hernnson, Paul, Benjamin Bederson, Frederick Conrad, Peter Francia, Bonshin Lee, Richard Niemi, Robert Sherman and Michael Traugott, 2005. Social Science Computer Review. 23:274-392.

Institute of Electrical and Electronics Engineers. 2003. Usability and Accessibility Standards.

Kimball, David C., Chris T. Owens, and Katherine M. Keeney. Forthcoming. "Unrecorded Votes and Politial Representation." In Counting Votes: Lessons from the 2000 Presidential Election in Florida, ed. Robert P. Watson, Gainesville: University Press of Florida, pp 135-50.

Knack, Stephen and Martha Kropf. 2003. "Voided Ballots in the 1996 Presidential Election: A County-Level Analysis," Journal of Politics 65:881-98.

Laskowski, S. J., M. Autry, J. Cugini, W. Killam, \& J. Yen. (2004). Improving the usability and accessibility of voting systems and products. NIST Special Publication 500-256.

Nichols, Stephen M. and Gregory A. Strizek. 1995. "Electronic Voting Machines and Ballot Roll-Off." American Politics Quarterly. 23:300-18.

Roth, S. K. (1998). Disenfranchised by design: voting systems and the election process. The Information Design Journal, 9. Retrieved from < http://www.informationdesign.org/pubs/roth1998.html>.

Shocket, Peter A., Neil R. Heighberger, and Clyde Brown. 1992. "The Effect of Voting Technology on Voting Behavior in a Simulated Multi-Candidate City Council Election: A Political Experiment of Ballot Transparency," Western Political Quarterly. 45:521-37.

Tomz, Michael and Robert P. Van Houweling. 2003. "How Does Voting Equipment Affect the Racial Gap in Voided Ballots?" American Journal of Political Science. 47:46-60.

Wand, Jonathan N., Kenneth W. Shotts, Jasjeeet S. Sekhon, Walter R. Mebane, Jr., Michael C. Herron, and Henry E. Brady. 2001. "The Butterfly Did It: The Aberrant Vote for Buchanan in Palm Beach County, Florida," American Political Science Review. 95:793-810.

Address reprint requests to: Robert M. Stein Department of Political Science MS 24

Rice University Houston, Texas 77251

E-mail: stein@rice.edu 